\title{
NOTAS
}

\section{LA SEGUNDA ESPADADA: FOLKLORE MÁGICO EN UN ROMANCE SEFARDÍ}

El romance de La Gallarda matadora (i-a) es muy raro en la tradición sefar díl. Manuel Manrique de Lara recogió en Salónica en 1911 las cuatro versiones, aún inéditas, que actualmente pertenecen a los riquísimos fondos del Archivo Menéndez Pidal (CMP N3) 2. De la tradición turca, probablemente

1 Nos referimos a las siguientes colecciones de romances: EMma AdATTO [Schlesinger], A study of the linguistic characteristics of the Seattle Sefardi folklore, tesis de maestría, Umversity of Washington, 1935; N. A LONSO CORTÉs, "Romances tradicionales", RHi, 50 (1920), 198-268; RINA BENMAYOR, Romances judeo-españoles de Oriente: nueva recolección, Gredos, Madrid, 1979; THEÓPHILO BRAGA, Romanceiro geral português, 3 tomos, $2^{\text {a }}$ ed., Lisboa, 1906-1909; CMP = SAmuEL G. ARMISTEAD et al., El romancero judeo-español en el Archivo Menéndez Pidal (Catálogo-índice de romances y canciones), 3 tomos, C.S.M.P., Madrid, 1977; A. DANON, "Recueil de romances judéo-espagnoles chantées en 'Turgie", REu, 32 (1896), 102-123 y 263-275; ibid., 33 (1896), 122-139 y 255-268; RODOlFo GIL, Romancero judéo-español, Madrid, 1911; AlBERTO HEMSI, Coplas sefardíes (Chansons judéoespagnoles) [pour chant et piano], 10 fascículos, Alejandría, Egipto, 1932-1938, 10 fascículos; Aubervilhers, France, 1969-1973; Arcadio de Larrea Palacín, Romances de Tetuán, 2 tomos, Madrid, 1952; JosÉ LeITE de VAsCONCELLOS, Romanceiro potuguês, 2 tomos, Universidade, Coimbra, 1958 1960; Marcelino Menéndez Pelayo, "Romances castellanos tradicionales entre los judíos de Levante", Antología de pretas líricas castellanos, t. 9, C.S.I.C., Santander, 1945, po. 387.439 (Edición Nacional de las Obras completas de Menéndez Pelayo); Juan Menéndez Pidal, Poesía popular: colección de los viejos romances que se cantan por los asturianos. . ., Madrid, 1885; MP $=\mathrm{R}$. MENÉNDEZ PIDAL, "Catálogo del romancero judío-español", Cultura Española, 4 (1906), 1045-1077; ibid., 5 (1907), 161-199; А.W. MUNTHE, "Folkpoesi frản Asturien", Upsala Universitets A rsskrift: Filosofi, Sprakvetenskap och Historiska Vetenskaper, 5 (1887), 105-124; Romances tradicionales y canciones narrativas existentes en el folklore español. (Incipit y temas), Instituto Español de Musicología, Barcelona, 1945; DAvid ROMEY, A study of Spanish tradition in isolation as found in the romances, refranes, and storied folklore of the Seattle Sephardic community, tesis de maestría, University of Washington, 1950; C Sampedro y Folgar, y J. Filgueira Valverde, Cancionero musical de Galicia, 2 tomos, Madrid, 1942; Terra de Melide, Compostela, 1933, nueva ed., La Coruña, 1978.

Las formas marroquí y peninsulares de La Gallarda matadora representan un sub-tipo radicalmente distinto en que falta por completo el motivo de la mujer medio bestia. Véanse LARREA, pp. 131-132; CMP N3; Alonso Cortés, p. 220; J. Menéndez Pidal, núms. 51-53; Munthe, núm. 9; Romances tradicionales y canciones narrativas, num. 62; SAMPEdro, t. 1, p. 123; Terra de Melide, p. 488 (núm. 10); BraGA, t. 3, pp. 333-335; LeITe de VASCONCELlos, núms. 587-588, 591, 595597. Úlimamente se han publicado varias versiones adicionales: FLOR SALAZAR y ANA VALEN GIANO, "El romancero aún vive. Trabajo de campo de la CSMP: 'Encuesta Norte-77' ", CIR(2), 2, 361-421: 411-412; Suzanne H. Petersen et al., Voces nuevas del romancero castellano leonés, t. 2, Gredos, Madrid, 1982, núm. 55, 1-9; Revista de Folklore, Valladolid, 1981, núm. 4, p. 33; ibid., 1982, núm. 20, 47-48, 69; MANuEl Viegas Guerreriro, Pitóes de Júnias: Esboço de monografia etnográfica, Lisboa, 1981, p. 259. Difieren relativamente poco entre sí las formas marroquí y peninsulares.

2 Nuestro amigo Jesús Antonio Cid tiene en preparación una edición exhaustiva de los romances de la Gallarda y de otras mujeres matadoras. Se publicará en la serie Romancero tradicional 
en Edirne, recogió el romance Abraham Danon (núm. XXIII) a finales del siglo pasado ${ }^{3}$. De Estambul proviene la versión que publica Alberto Hemsi (núm. XLIX). Turcos también son los textos que recogen, de inmigrantes de los pueblos del Bósforo, en Seattle (Washington, E.E.U.U.), Emma Adatto [Schlesinger] (núm. VI), David Romey (núm. XVIII) y Rina Benmayor (núms. $17 a-17 b)$. También de Estambul es el breve fragmento que editamos recientemente de una grabación fonográfica comercial de principios de siglo, cantada por el famoso Haim Effendi ${ }^{4}$. La única versión que logramos grabar en nuestras encuestas de campo con sefardíes orientales fue cantada por la Sra. Lea Sadis Israel, de 66 años, en Seattle, el 26 de agosto de 1958. De la misma informante ya había recogido el romance E. Adatto (durante los años 1930; versión inédita) y, después de nuestra encuesta, lo volvió a recoger Rina Benmayor (núm. 17c) de la misma señora, el 18 de junio de 1973. La Sra. Israel nació en Rodas, pero La Gallarda matadora no es propia de la tradición de esa isla. En rodas nuestras encuestas con numerosas y buenas cantoras rodeslías, no lo encontramos nunca. Según razonablemente supone Rina Benmayor, la Sra. Israel habrá aprendido el romance en Seattle de alguna amiga suya proveniente del Bósforo.

La Gallarda matadora, en su modalidad judeo-oriental, nos evoca una mujer horrenda y homicida - especie de "Linda Melosina" a lo tremendo-, monstruosa combinación de ser humano y bestia o culebro ${ }^{5}$. He aquí el romance según nos lo cantó la Sra. Israel en 1958:

\footnotetext{
de las lenguas hispánicas. Véase BenMayor, op. cit., pp. 134-137. Para el fragmento de Haim Effendi, véanse nuestras notas (con IsRael J. KATZ), "Sobre la antigua discografía sefardí y el Romancero", LCn, 9 (1981), 138-144, y "Sovre romansas djudeo-espanyolas en diskos fonografikos antiguos", Ali Yerushalayim, 1981, núm. 9, 13-16.

3 La versión de Danon se reproduce en MP 89 y en Menéndez Pelayo 34. La lamentable antología de Gil (núm. XXIII) recoge las reproducciones de Menéndez Pidal y Menéndez Pelayo como si se tratara de dos versiones distintas. ¡ $\mathrm{Ni}$ siquiera leyó los textos que envió a la imprenta!

${ }^{4}$ Nótese el detallado y penetrante estudio de Rina BENMAYOR, op. cit., pp. 134-317.

${ }_{5}^{5}$ Para el relato de Melosina, quien todos los sábados, por una maldición, está condenada a transformarse en culebra del ombligo para abajo, véase A. D. DEYermond, "La historia de la linda Melosina: Two Spanish versions of a French romance", HRH, pp. 57-65: 58. Como culebra pura y simple huye volando por la ventana al final del relato y en esa transformación sigue apareciendo en los alrededores del castillo de Lusignan como agüero de la próxima muerte de los dueños del castillo. Como una especie de dragón con alas figura en el famoso libro de horas del duque de Berry. Véase Edmond PoGnon, ed., Les très riches heures du Duc de Berry. 15th-century manuscript, trad. D. Macrae, New York, 1979, pp. 20-21. Para grabados góticos en que se ve a la Melosina en su modalidad de mujer-serpiente, véanse JOHN ASHTON, Romances of chivalry, New York, 1887, pp. ii y 65; Alan C. Kors y EDWard Peters, Whitchcraft in Europe, 1100-1700: A documentary history, Philadelphia, 1972, p. 214. Sobre la leyenda, véanse Laura A. Hibbard, Mediaeval romance in England, New York, 1924, p. 207, n. 14, así como el antiguo, pero aún muy útil, estudio de Sabine Baring-Gould, Curious myths of the Middle Ages, Oxford-Cambridge, 1881, pp. 471-523. Para otros seres semejantes, nótese la Troll hembra, mitad ser humano, mitad bestia, que cita NORA K. CHADWrCK, "The monsters and Beoreulf", The Anglo-Saxons: Studies in some aspects of their history presented to Bruce Dickins, London, 1959, pp. 171-203: 192. Sobre el motivo, véanse también Claude LÉvi-Strauss, Tristes tropiques, Paris, 1955, p. 242, o bien la trad, al inglés de J y D. Weightman, London, 1973, p. 233; STrTh ThOMPSON, Motif-index of folk-literature, 6 tomos, Bloomington, 1955-1958, B20. Beast-men-B29.9 (sobre todo, B29.2: Half-woman, half serpent); F526.1. Typhon. Human down to thighs; coil of vipers below; GERALD BORDMAN, Motif-index of the English metrical romances, Helsinki, 1963, ${ }^{*}$ F526.7. Man-upper half human, lower half wolf.
} 
$Y$ de enfrente la veigo venir

2 Le demandí si era cazada. Siete maridos ha tomado;

4 y por no hazerme el mi dicho -Y yo te haré el tu dicho

6 -Tenéme esta linda candela y de culebras y alacranes

$8 Y$ fin que se haze la sena $Y$ del ombligo para arriva,

10 Y del ombligo para abaxo, Y yo vezí de la madre,

12 Y ya le dio una d'eya -Y dame una otra d'eya, como el grano de agranada:

- Cazada, por los mis pecados. todos los siete eran matados

y ni menos el mi comando. y también y el tu comando.

y vos haré la linda sena $y$ todo modo de animales. y vos haré la linda cama.una linda dama sería. un negro animal sería. que la mujer se echa delantre. y la hizo media por media. una ves me parió mi madre ${ }^{6}$.

Exclusivos de esta versión de la Sra. Israel son los enigmáticos vv. 12 y 13, documentados en forma idéntica en los textos de Adatto y Benmayor. Hasta la fechà, según creemos, han quedado sin explicar. ¿Qué pide la mujermonstruo? ¿Por qué, una vez que va la ha partido en dos, aún insta al protagonista a que le dé otra segunda espadada? ${ }^{7}$ Unos textos de proveniencia lejana de la Península Ibérica y del Mar Egeo, tanto en una dirección como en otra, nos aclaran perfectamente el pasaje.

El Mabinogi es una colección de narraciones mítico-heroicas en galés medieval y de fecha muy controvertida. Sus manuscritos y fragmentos se distribuyen entre los siglos XIII y XV, pero a todas luces la colección recoge materiales narrativos mucho más antiguos. La primera "rama" del Mabinogi se ocupa de las aventuras de Pwyll, príncipe de Dyvet: Un día, Pwyll sale de caza, suelta sus podencos, los sigue y se separa de sus compañeros. Al entrar en un claro en el bosque, de repente se le aparecen unos podencos rarísimos, de un color brillante insólito y de obvio carácter sobrenatural. Estos perros estaban en el acto de alcanzar y arrastrar al suelo a un ciervo. Pwyll, sin pensarlo bien, ahuyenta a la jauría extraña, haciendo lugar para que sus propios perros se ceben de la presa. En este momento, se le aparece un jinete. Resulta que es el rey Arawn, soberano de un reino sobrenatural. Por el asunto de los perros, se siente agraviadísimo. La única solución que a Pwyll le queda para estar en paz con el rey Arawn será encontrarse en batalla campal singular con Hafgan, otro rey de Annwvyn, tierra del propio Arawn, y enemigo mortal de éste. Conciertan el trato Pwyll y Arawn. He aquí el consejo que el rey sobrenatural el da Pwyll sobre su proyectado paso de armas con Hafgan:

6 La versión de E. Adatto, pese a más de dos décadas por medio, es esencialmente idéntica a la nuestra: en el v. la reza vedo por veigo y antopone el v. 11 a los vv. 9 y 10 . La versión de R. Benmayor omite los vv. 5, 9, 10 y 11 y trae algunas ligerísimas diferencias verbales y fonológicas. La Sra. Israel nos cantó el romance dos veces. La segunda presentación trae las siguientes variantes: $3 a$ Que siete maridos; $6 b$ vos haré esta linda sena; $7 b$ alimales. La forma vezi (v. $11 a)$ se basa seguramente en ambezar 'aprender' (véase M. LuRIA, $A$ study of the Monastir dialect. . ., New York, 1930, s.v. ambizar).

7 Que "ella" se refiera a una espada es indudable, dadas las lecturas de otras versiones judeoorientales: "Desenvainó la su espada, / la cabeza le cortaba" (DANON); "Desvainó la suya espada / le cortó suya gargantera" (HEMSI); "Ya travó y la su 'spada' / la caveza le tomava" (BENMAYOR 17a). 
"El encuentro entre él y yo está fijado esta misma noche dentro de un año en el vado. Y tú estarás allí con mi apariencia; y le darás un solo golpe y no sobrevivirá, y te pedirá un segundo golpe, pero no se lo des por mucho que te suplique. Yo, en cambio, por más que lo golpeé, no conseguí nada, porque al día siguiente combatía conmigo mejor que la vez anterior" ${ }^{\prime 8}$.

A su debido tiempo y vez, Pwyll (transformado su aspecto por arte de magia para que se parezca a Arawn) se encuentra con Hafgan en el vado:

En seguida, los dos reyes se acercan hasta el centro del vado. En el primer ataque, el hombre que ocupaba el lugar de Arawn alcanza a Hafgan en medio del brocal del escudo de tal forma que lo partió en dos, y rompió todas las armas y Hafgan cayó al suelo, cuan largo era su brazo y sulanza, por encima de las gru-

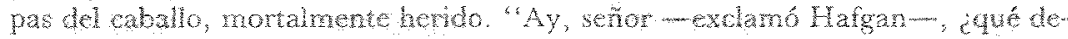
recho tenes para matame? Nada te reclamaba; que yo sepa, no hay motivo para darme muerte. En nombre de Dios, ya que has comenzado mi nuerte, llevala a cabo:"9.

Pwyll se niega a darle el segundo golpe y Hafgan se dirige a sus nobles: "Mis nobles fieles, .. . sacadme de aquí. Mi muerte ha sido consumada" (Cirlot, p. 82). ¿Por qué? Tengamos en cuenta, por ahora, que tanto Arawn como Hafgan son reyes sobrenaturales de un reino mágico y maravilloso.

Dos textos tradicionales árabes ayudan a aclarar tanto nuestro romance sefardí como el relato mítico-heroico galés. En la Historia del príncipe Saif alMulük y de la princesa Bad" 'at al-Janäl (Las 1001 noches, noches 757-778), Sa'id, el hermano de Saif al-Mulik, experimenta unas aventuras marítimas, calcadas, en algún caso, sobre las homéricas de Ulises 10 . Tras naû́ragar, $5 a^{\circ i d}$ se aferra a un madero y logra llegar a una isla, donde se encuentra con un gigante antropófago, pastor de ovejas (obvio recuerdo del Cíclope, Polifemo): "una persona de elevada estatura, de larga barba, orejas colgantes y ojos que parecían tizones encendidos. Llevaba por delante un rebaño numeroso al que apacentaba". Resulta que el gigante es un ghül, que invita a los seres humanos a su cueva y les ofrece una bebida venenosa que los ciega, para luego poderlos matar y comer. Sa'id vierte la bebida por un hoyo en la tierra, finge quedar ciego, coge dos espetones del fuego y - a lo Uilises- ciega con ellos al ghül. Siguiendo las indicaciones de otro náufrago, ya cegado y preso también por el $g h \bar{u} l, S a{ }^{i} \bar{d}$ se dirige al fondo de la cueva, donde encuentra una espada. El ciego le aconseja en los términos siguientes, según lo narra Sa‘id:

8 Traducimos al español la versión inglesa de P. K. FORD, The Mabinogi and other Medieval Welsh tales, Berkeley-Los Angeles, 1977, p. 38. Sobre el problema de la fecha, véase la p. 2. También tenemos a la vista otras dos traducciones: The Mabinogion: Mediaeval Welsh romances, tr. $\mathrm{C}$. Guest, Long Acre, 1910, p. 5; The Mabinogion, tr. J. Ganz, Baltimore, 1976, p. 48.

9 FORD, p. 40; Guest, p. 7; GANZ, p. 49

10 Para la influencia de la Odisea en Las 1001 noches, consúltese GuSTAve E. VON Grune. BAUM, "Creative borrowing: Greece in the Arabian nights", Medieval Islam: A study in cultural orientation, 2nd. ed., Chicago, 1966, pp. 294-319. Incluso, sn una de las variantes árabes, el monstruo se llama Eli-Faniun = Polýphémos (p. 303). Ei mismo relato "polifémico", pero sin los motivos de la espada y del solo golpe, se encuentra también en el tercer viaje de Sindbad el marinero (noches 546-547). Véanse las traducciones de VERNET, t. 2, pp. 764-769; PAYNE, t. 5, pp. 171-174; BURTON, t. 6, pp. 24-28; LANE, t. 3, pp. 25-28; LITTMANN, t. 4, pp. 129-134 (citas cabaies en la nota siguiente). 
"Coge. . [ [la espada] bien y golpéale en la cintura: morirá en el acto"'. Me acerqué hacia él, corrí en pos suyo. . . Yo me aproximé [al ogro], le di un mandoble en la cintura y quedó partido en dos mitades. Chilló y dijo: “¡Hombre! ¡Si quieres matarme dame otro golpe!' Me disponía a darle el segundo mandoble cuando aquel que me había indicado dónde estaba la espada gritó: “¡No se lo des! ¡No moriría! ¡Al contrario, volvería a la vida y nos mataría!". . . Yo me atuve a las instrucciones que me daba y no le volví a herir. El maldito expiró ${ }^{11}$.

Resulta que con seres sobrenaturales el primer golpe mata, mientras que el segundo sana. Si nos hicieran falta más comprobantes, he aquí otro texto árabe, recogido ya en pleno siglo xx, entre 1926 y 1931, por el inigualado explorador del Rub' al-Khali, Bertram Thomas: El fortísimo campeón, Dhiyāb bin Ghānim, noble de la heroica tribu de los Ban̄̄ Hilāl (cuyas aventuras constituyen una amplísima epopeya cantada aún hoy en día en muchas partes del mundo árabe $)^{12}$, se encuentra con un monstruoso djinn, que enfila los camellos con su ingente lanza y los come crudos, dejando los restos, a medio comer, esparcidos alrededor de un enorme pozo donde tiene su guarida:

Así que Dhiyāb cabalgó en la mula y llegó al pozo. En cuanto se acercaba el djinn se puso de pie para revelar su estatura monstruosa, pues la mitad de su cuerpo estaba fuera del pozo y la otra mitad dentro. $\mathrm{Y}$ el djinn gritó: "¡Oh, ha! Ya Dhiyāb bin Ghānim, ¿has venido para comer o para matar?'” Dhiyāb respondió: "He venido tanto para comer como para matar". Y desenvainando su espada, dio un gran golpe al djinn y lo cortó en dos mitades, de modo que una mitad se quedó dentro del pozo y la otra quedó fuera, caída [en el suelol. Dijo la mitad superior del djinn: "Hain, golpea una segunda vez". Pero Dhiyāb respondió:

11 J. Vernet (trad.), Las mil y una noches, $3^{\text {a }}$ ed., 3 tomos, Barcelona, 1968, t. 3, pp. 295296 (noches 772-773). Compárense también J. PAYNE (trad.), The book of the thousand nights and one night, 9 tomos, London, 1882-1884), t. 7, pp. 102-103, y R. F. BuRTON (trad.), The book of the thousand nights and a night, 10 tomos, Stoke Newington, 1885, t. 7, p. 361. Téngase en cuenta además la excelente traducción alemana de E. LitTMann, Die Erzählungen aus den Tausendundein Nächten, 6 tomos, Wiesbaden, 1953, t. 5, pp. 289-291 ("Triff ihn nicht zum zweiten Male; sonst stirbt er nicht, nein, dann wird er am Leben bleiben. . ."). La traducción de E. W. LANE, The thousand and one nights, 3 tomos, London, 1889), basada en un ms. distinto, recoge otros relatos de canibalismo que no se parecen al que aquí nos ocupa (t. 3, pp. 304-306). Sobre las versiones occidentales de las 1001 noches, consúltense MIA I. GERHARDT, The art of story-telling: A literary study of the "Thousand and one nights", Leiden, 1963, pp. 67-113, y CHRISTOPHER KNIPP, "The Arabian nighis in England: Galland's translation and its successors", Journal of Arabic Literature, 5 (1974), 44-54; también JORGE LuIS BORGES, "Los traductores de las 1001 noches", Historia de la eternidad, Buenos Aires, 1966, pp. 99-134, y "Las mil y una noches", Siete noches, México, 1980, pp. 55-74.

El motivo del encuentro de la espada en la cueva en el relato árabe es curioso, pues recuerda tanto la antigua épica anglo-sajona de Beowulf como su congénere en la cuentística popular internacional, El hijo del oso (Bear's-Son) - Juan el oso, en un contexto hispánico. Sobre el caso, véase R. W. Chambers y C. L. Wrenn, Beowulf: An introduction to the study of the poem. . , 3rd ed., Cambridge, 1959 , pp. 62, 77, 371-373, 376, 468 et alibi. Lo notable es que, en una variante rusa inédita, resumida en Chambers y Wrenn, el héroe ha de matar a la monstruosa Baba Yaga con un solo golpe de la espada hallada en la cueva: "Agarra la espada y córtale la cabeza de un solo golpe" ("Seize the sword and cut her head off at one blow", p. 373). Obviamente se trata del mismo motivo que aquí nos interesa (aunque no se ofrece ninguna explicación sobre el caso). Para Bear'sSon y Juan el oso, véanse Aurelio M. EsPinOSA, Cuentos populares españoles, 3 tomos, Madrid, 19461947, t. 1, núms. 133-135; ANTTi AARNE y STITH THOMPSON, The types of the folktale, 2nd ed., Helsinki, 1930, núm. 301.

12 Véase Serafín Fanjul, Literatura popular árabe, Madrid, 1977, pp. 135-146. Para el estudio de la gesta de los Banu Hilal, va a ser indispensable la monografía pionera de BRIDGET CON. NELLY, In praise of illiterature: Cultural polemics and the Arabic epic tradition (en preparación). 
"Ma thinni, wa la zinni, wa la akl al djins ni',
"No repito,

ni hago fornicio,

ni [soy] comida para mi [ = tu] raza",

pues Dhiyāb sabía lo que todos saben, que mientras un golpe mortal mata a un djinn, dos golpes sin duda resucitan a dos djinns ${ }^{13}$.

Hace poco, nuestra colega, la profesora Mercedes Díaz Roig, llamó la atención sobre la necesidad de enfocar desde una nueva perspectiva los elementos mágicos y sobrenaturales en el Romancero ${ }^{14}$. El contraste entre la tradición hispánica, donde se ha pretendido que tales elementos escaseaban, y otras ramas de la balada europea, como la escandinava y la anglo-escocesa, donde son relativamente más abundantes ${ }^{15}$, no es por lo tanto tan grande como se ha venido diciendo. Valga el presente caso como otro ejemplo más en favor de semejante $\operatorname{tesis}^{16}$.

\section{S. G. Armistead y J. H. Silverman}

Üniversity of California, Davis.

University of California, Santa Cruz.

\section{EL CROTALÓN: EL TEXTO Y SUS SENTIDOS}

El Crotalón ha sido una obra tradicionalmente mal editada. Desconocida hasta finales del siglo pasado, contó después con editores poco rigurosos que abordaron el trabajo sin plantearse, o sin resolver, los problemas filológicos

13 Traducimos al español la versión en inglés de B. Thomas, Arabia Felix: Across the 'Empty Quarter', New York, 1932, p. 279. Que sepamos, el texto original árabe nunca se ha publicado. Es notable, en esta variante, que el segundo golpe no sólo sana al dïnn, sino que multiplica la especie. La traducción de la coplilla resulta problemática. Las palabras claves corresponden en árabe clásico a ithnayn 'dos'; zanà 'fornicar'; akl 'comida'; jins 'raza, especie', pero los versos dialectales se resisten a todo análisis gramatical. La razón de ello es la constante alteración y distorsión de las palabras en posición rimada que caracteriza la poesía popular en árabe vulgar. Sobre el caso, consúltese el artículo fundamental de P. CACHlA, "The Egyptian Mawwāl: Its ancestry, its development and its present forms', Journal of Arabic Literature, 8 (1978), 77-103. Nos complace agradecer a nuestros colegas, Bridget Connelly y James T. Monroe, sus generosas y eruditas orientaciones respecto a problemas árabes, tanto literarios como lingüísticos.

Los textos citados en el presente artículo provienen de nuestras propias lecturas. Se aducen abundantes ejemplos adicionales en el Motif-index de STITH THOMPSON: C742. Tabu: striking monster twice. Though monster begs that hero strike him again, hero refuses. Monster would otherwise revive; Ell.1. Second blow resuscitates. First kills.

${ }_{14}$ M. DÁAZ RolG, "Lo maravilloso y lo extraordinario en el romancero tradicional", en Deslindes literarios, El Colegio de México, México, 1977, pp. 46-63.

15 Véanse, por ejemplo, AXEL OLRIK, Nordens trylleviser, eds. Anders Bjerrum e Inger M. Boberg, Copenhague, 1934 y LOWRY C. WIMBERLY, Folklore in the English and Scottish ballads, New York, 1959

16 Véase también nuestro libro, En torno al romancero sefardí: Hispanismo y balcanismo de la tradición judeo-española, C.S.M.P., Madrid, 1982, pp. 105-109. 